\title{
COVID-19 e saúde do trabalhador da saúde no Estado do Rio de Janeiro
}

\author{
COVID-19 and health of health workers in the State of Rio de Janeiro
}

COVID-19 y salud de los trabajadores de la salud en el Estado de Río de Janeiro

\author{
Diego de Oliveira da Cunha \\ ORCID: https://orcid.org/0000-0002-0738-046X \\ Centro Federal de Educação Tecnológica Celso Suckow da Fonseca, Brasil \\ E-mail: diego.cunha@aluno.cefet-rj.br \\ Flaviane Santos da Costa \\ ORCID: https://orcid.org/0000-0002-6859-9852 \\ Centro Federal de Educação Tecnológica Celso Suckow da Fonseca, Brasil \\ E-mail: flaviane.costa@aluno.cefet-rj.br \\ Graciane Oliveira Costa \\ ORCID: https://orcid.org/0000-0001-5104-4132 \\ Centro Federal de Educação Tecnológica Celso Suckow da Fonseca, Brasil \\ E-mail: graciane.oliveira07@gmail.com \\ Cristina Fernanda Viana da Silva \\ ORCID: https://orcid.org/0000-0002-8497-4552 \\ Centro Federal de Educação Tecnológica Celso Suckow da Fonseca, Brasil \\ E-mail: crisferviana@hotmail.com \\ Júlio Cesar Santos da Silva \\ ORCID: https://orcid.org/0000-0001-7223-3717 \\ Centro Federal de Educação Tecnológica Celso Suckow da Fonseca, Brasil \\ E-mail: julio.silva@cefet-ri.br \\ Cristiane Rosa Magalhães \\ ORCID: https://orcid.org/0000-0002-7231-3431 \\ Centro Federal de Educação Tecnológica Celso Suckow da Fonseca, Brasil \\ E-mail: cristiane.magalhaes@cefet-rj.br
}

\begin{abstract}
Resumo
A situação pandêmica instaurada no mundo devido ao surgimento das doenças e seus agravos decorrente da COVID19 trouxeram diversas mudanças de paradigmas na esfera individual e coletiva das sociedades, que de forma repentina e inesperada se encontrou frente a uma nova realidade. Diante do exposto, esta pesquisa tem teve como objetivo principal analisar a segurança à exposição aos riscos ocupacionais dos diversos trabalhadores de saúde que atuam diretamente frente à pandemia do COVID-19 na instância de saúde do Rio de Janeiro. Já como objetivos específicos: será mensurar o seu efeito e assim comparar com o alicerce ofertado pela Gestão de Saúde, visando, dessa forma, demonstrar a relevância da prevenção e promoção à saúde do trabalhador de saúde frente à pandemia do COVID-19, o que consequentemente contribuirá para a saúde social e para o desenvolvimento regional. A presente pesquisa tem natureza quantitativa e de acordo com a taxinomia, em relação aos fins, trata-se de uma pesquisa descritiva, técnica utilizada foi a bola de neve (snowball). $\mathrm{O}$ instrumento escolhido para essa pesquisa foi um questionário criado através do Google Forms. A pesquisa revela que a 20\% dos participantes não foram apresentados os protocolos de segurança para realizarem realização de suas atividades funcionais, e que os protocolos de segurança não estão sendo implementados de maneira satisfatória no exercício profissional por intermédio das instituições, como também vem apontar um número expressivo de participantes que não receberam suporte médico, ou outro apoio por parte da empresa devido a exposição à COVID-19.
\end{abstract}

Palavras-chave: COVID-19; Trabalhadores da saúde; Segurança; EPI.

\begin{abstract}
The pandemic situation established in the world due to the emergence of diseases and their injuries resulting from COVID-19 brought several paradigm shifts in the individual and collective sphere of societies, which suddenly and unexpectedly found themselves facing a new reality. Given the above, this research has as its main objective to analyze the safety of exposure to occupational risks of the various health workers who work directly against the COVID-19 pandemic in the health instance in Rio de Janeiro. As specific objectives: it will measure its effect and thus compare it with the foundation offered by the Health Management, aiming, in this way, to demonstrate the relevance of prevention and promotion of the health of the health worker in the face of the COVID-19 pandemic, which consequently it will contribute to social health and regional development. This research is quantitative in nature and according to taxonomy, in relation to the purposes, it is a descriptive research, the technique used was the snowball. The instrument chosen for this research was a questionnaire created through Google Forms. The survey reveals that $20 \%$ of the participants were
\end{abstract}


not presented with the safety protocols to carry out their functional activities, and that the safety protocols are not being satisfactorily implemented in the professional practice through the institutions, as it also points out a significant number of participants who did not receive medical support, or other support from the company due to exposure to COVID- 19 . Keywords: COVID-19; Health workers; Security; EPI.

\section{Resumen}

La situación de pandemia instaurada en el mundo por la aparición de enfermedades y sus lesiones derivadas del COVID19 trajo varios cambios de paradigma en el ámbito individual y colectivo de las sociedades, que repentina e inesperadamente se encontraron frente a una nueva realidad. Dado lo anterior, esta investigación tiene como principal objetivo analizar la seguridad de exposición a riesgos laborales de los distintos trabajadores de la salud que actúan directamente contra la pandemia COVID-19 en la instancia de salud de Río de Janeiro. Como objetivos específicos: medirá su efecto y así compararlo con el fundamento que ofrece la Gerencia de Salud, buscando, de esta manera, demostrar la relevancia de la prevención y promoción de la salud del trabajador de la salud ante el COVID- 19 pandemia, que en consecuencia contribuirá a la salud social y al desarrollo regional. Esta investigación es de naturaleza cuantitativa y según taxonomía, en relación a los propósitos, es una investigación descriptiva, la técnica utilizada fue la bola de nieve. El instrumento elegido para esta investigación fue un cuestionario elaborado a través de Google Forms. La encuesta revela que al $20 \%$ de los participantes no se les presentaron los protocolos de seguridad para el desempeño de sus actividades funcionales, y que los protocolos de seguridad no se están implementando satisfactoriamente en la práctica profesional a través de las instituciones, como también señala un número significativo de participantes que no recibieron apoyo médico u otro apoyo de la empresa debido a la exposición al COVID-19.

Palabras clave: COVID-19; Trabajadores de la Salud; Seguridad; EPI.

\section{Introdução}

Autoridades de saúde chinesas enviaram, em 31 de dezembro de 2019, relatórios à Organização Mundial da Saúde (OMS) sobre a presença de casos de pneumonia por causa desconhecida na cidade de Wuhan, China, e subsequentemente as mesmas autoridades identificaram um novo coronavírus SARS-Cov-2, responsável pela Síndrome Respiratória Aguda Grave (Rizzo et al. 2020).

Foi confirmado no Brasil o primeiro caso importado do novo coronavírus, em fevereiro de 2020, na cidade de São Paulo. O portador havia chegado da Itália apresentando a síndrome compatível com a doença causada pelo coronavírus: febre, tosse seca, dor de garganta e coriza (Ensp, 2021).

Segundo a Organização Mundial de Saúde, a situação atual em 04 de junho de 2021 apresenta 171.782 .908 casos confirmados da doença no mundo e 3.698,621 mortes confirmados. No Brasil tem-se 16.720.081 casos confirmados e 467.706 mortes confirmadas segundo OMS, até o dia 04 de junho de 2021. Já no estado do Rio de Janeiro temos 880.267 idem casos confirmados e 51.419 idem casos de mortes confirmados (Ministério da Saúde, 2021).

A situação pandêmica instaurada no mundo devido ao surgimento das doenças e seus agravos decorrente da COVID19 trouxeram diversas mudanças de paradigmas na esfera individual e coletiva das sociedades, que de forma repentina e inesperada se depararam frente a uma nova realidade. Essa exigência para a mudança de comportamento e de hábitos, viera permear dificuldades de adaptação por conta das adversidades e desigualdades excludentes, onde a vida, mesmo que sem o uso efetivo dos protocolos necessários para evitar o contágio e a propagação desse vírus, ainda sim era buscada, ao passo que metas de prioridades passariam a ser estabelecidas no intuito de garantir a sobrevivência dos seres (Helioterio et al. 2020).

Estudo produzido por Melo et al. (2020a) demonstram que os seres humanos nesse período de pandemia vêm se confrontando com interrogações que podem repercutir tanto na sua vida profissional, quanto na esfera pessoal, dessa forma podendo trazer impactos psicossocial, reações e sensações das mais diversificadas de acordo com as especificidades do indivíduo. O medo, a morte, a doença, a transmissão e a cura, são situações adversas passíveis de questionamentos constantes que circundam a subjetividade das pessoas.

Incluindo a classe trabalhadora nesse contexto de pandemia, e reconhecendo o potencial e a importância das atividades laborativas, torna-se primordial garantir os preceitos contidos na Política Nacional de Saúde do trabalhador e da trabalhadora. É preciso primar pelo "desenvolvimento da atenção integral à saúde do trabalhador, com ênfase na vigilância, visando a promoção 
e a proteção da saúde dos trabalhadores e a redução da morbimortalidade decorrente dos modelos de desenvolvimento e dos processos produtivos" (Brasil, 2012).

Quando o assunto são os profissionais da saúde, é primordial estabelecer diretrizes básicas para a implantação das medidas de proteção à segurança e à saúde, conforme definido na norma regulamentadora NR-32. Esta norma obriga os serviços de saúde a adequarem os ambientes de trabalho e a fornecerem todos os equipamentos de proteção individual necessários, bem como a capacitação contínua, a fim de que haja uma prevenção e adoção de medidas de proteção e controle de forma apropriada aos trabalhadores (Preven, 2020). Lima Barroso et al. (2020), compreendem que os profissionais do SUS exercem atividades laborativas com maior potencial no combate à pandemia.

Dessa forma, Melo et al. (2020b) pontuam que é necessário considerar que nesse período de pandemia da COVID- 19, o trato ao trabalhador da saúde demanda uma atenção específica, pois estes estão diante de uma carga emocional intensa ficando mais sujeitos aos impactos em sua saúde mental. Campion et al. (2020) também convergem com essa afirmação, pois concebem que os profissionais de saúde fazem parte do grupo mais suscetível aos efeitos do COVID-19 no quesito saúde mental.

Ao considerar os serviços de saúde, logo compreendemos a importância das intervenções nesta área, pois esse serviço se torna primordial diante da essencialidade do trabalho e por se tratar de vidas. Entretanto, para se alcançar a eficiência dos serviços prestados, os profissionais devem ser alvos de intervenção inicial. Esse aspecto já viera a ser debatido em 2019 na $16^{\mathrm{a}}$ Conferência Nacional de Saúde, onde foi reconhecida a relevância dos profissionais da saúde e sendo deliberada a valorização e o cuidado com esse público "garantindo condições para que cuidem da vida e da saúde de todos e todas" (Conselho Nacional de Saúde, 2020).

Para de Lima Barroso et al. (2020), a pandemia exige uma gestão célere e eficiente, com mecanismos e tomada de decisão que venha garantir a proteção, condições de trabalho e qualidade de vida para os profissionais que exercem suas funções no âmbito da saúde, pois são estes que estão na linha de frente que poderão ou não proporcionar a qualidade dos serviços prestados, para isso eles devem ser cuidados, para cuidar de maneira efetiva.

Entretanto, algumas situações podem ter reflexos negativos na segurança dos profissionais de saúde, o que traz alerta para a necessidade de intensificação das medidas de prevenção e controle de novos casos de infecção pelo SARS-COV-2. A partir disso, considerando o período de incubação da doença, onde as manifestações clínicas podem não estar presentes, o que torna inviável o reconhecimento precoce e diagnóstico rápido dessa enfermidade, é que emerge a relevância das medidas de prevenção e controle durante a assistência, também para os trabalhadores da saúde que não estejam na linha de frente (Agência Nacional de Vigilância Sanitária, 2021).

Estudos evidenciam os riscos aos quais os profissionais da saúde estão expostos, demonstrando impactos físicos e psicológicos na vida destes. Os riscos laborais que advém das limitações do fornecimento dos Equipamentos de Proteção Individual- EPI, o pouco treinamento para atuação junto as demandas da COVID-19, o contato com os pacientes suspeitos e confirmados e a carga horária, são as causas mais citadas pelos trabalhadores da área da saúde que desencadeiam os agravantes psicológicos (Bezerra et al. 2020).

Os profissionais que estão na linha de frente apresentam o nível de exaustão emocional elevado (da Silva Veloso, 2020; Barello, Palamenghi \& Graffigna, 2020), decorrente de experiências psicológicas estressantes (Shah et al. 2021). Nesse sentido, torna-se necessária a oferta do suporte e medida que venha proteger e promover a saúde dos profissionais envolvidos no trato a COVID-19, englobando a preocupação com as questões físicas e psicológicas (Teixeira et al. 2020).

Procedimentos relacionados à saúde do trabalhador são obrigatórios e regulamentados por um documento denominado Norma Regulamentadora, as quais orientam esses processos. Essas normas devem ser observadas pelas organizações e pelos órgãos públicos da administração direta e indireta e por órgãos que possuam empregados regidos pela Consolidação das Leis do Trabalho (Cunha et al. 2021). 
A Norma Regulamentadora 32 é responsável por estabelecer as diretrizes básicas para que sejam implementados os meios tanto de segurança, quanto de saúde dos trabalhadores dos serviços de saúde, e daqueles que exercem atividades de promoção e assistência à saúde em geral. Para fins de aplicação dessa NR, entende-se como serviços de saúde qualquer edificação destinada à prestação de assistência à saúde da população, e todas as ações de promoção, recuperação, assistência, pesquisa e ensino à saúde em qualquer nível de complexidade (Norma Regulamentadora NR- 32, 2019).

As atividades relacionadas aos serviços de saúde são aquelas que apresentam um risco maior devido à possibilidade de contato com os micro-organismos encontrados no ambiente durante a atividade laboral, e com potencial de provocar doenças nos trabalhadores diretamente envolvidos com estes agentes: médicos, enfermeiros, técnicos e auxiliares de enfermagem, atendentes de ambulatórios e hospitais, dentistas, nutricionistas, fisioterapeutas, assistentes sociais e outros (Silva et al. 2016).

Os serviços de saúde possuem responsabilidades relacionadas à proteção à saúde do trabalhador. Dessas obrigações, destacam-se garantias de fornecimento gratuito de equipamentos de proteção individual adequado ao risco e em perfeito estado de conservação e funcionamento, a obrigatoriedade da notificação das doenças profissionais e das produzidas em virtude de condições especiais de trabalho, mesmo sendo suspeitas, a capacitação dos profissionais, principalmente quando são identificados novos riscos biológicos, garantia da avaliação periódica relacionada à saúde ocupacional e mecanismos para imunização contra agentes biológicos (Ministério da Saúde, 2020).

Protocolo é o levantamento de uma situação singular da assistência ou cuidado, contendo detalhes operacionais e especificações sobre o que se faz, quem faz e como se faz, direcionando os profissionais nas decisões de assistência para a prevenção, recuperação ou reabilitação da saúde (Conselho Regional de Enfermagem de São Paulo, 2017).

Os trabalhadores de saúde devem ter garantido o acesso aos documentos e adequado treinamento nas normas vigentes de manejo e tratamento dos casos de contágio pelo SARS-Cov-2 e adoecimento pela COVID-19 conforme divulgado pelo Ministério da Saúde, a Organização Pan-americana da Saúde e a Organização Mundial da Saúde, que recomendam a adoção dos meios de preservação da saúde desse grupo de colaboradores, envolvendo a saúde física e mental (CNS, 2020).

Segundo o protocolo de manejo clínico do coronavírus, são medidas a fim de evitar o contágio por vírus causadores de Síndrome Gripal entre os trabalhadores da saúde, a utilização de máscara cirúrgica, sendo a máscara N95 ou PFF2 somente para procedimentos produtores de aerossóis como exemplos a intubação e a aspiração aberta, a frequência da lavagem das mãos, a limpeza e desinfecção de objetos e superfícies tocados com frequência e o uso de luvas, óculos ou protetor facial e aventais descartáveis ( Secretaria de Atenção Primária à Saúde, 2020).

No Brasil, quatro vacinas contra a COVID-19 receberam autorização da Agência Nacional de Vigilância Sanitária (Anvisa): CoronaVac, vacina do Butantan produzida em parceria com a biofarmacêutica chinesa Sinovac, e os imunizantes das empresas AstraZenica, Pfizer e Janssen. Esses imunizantes foram desenvolvidos a partir de técnicas diferentes e testados em momentos e população diferentes, porém com rigor científico em todos os testes e dados que comprovem a sua eficácia e segurança (Guimarães, 2021).

A Campanha Nacional de Vacinação contra a COVID-19 teve início no dia 18 de janeiro de 2021 considerando como grupo prioritário os trabalhadores de saúde. Desses imunobiológicos, descrevem-se as de uso no Brasil: Sinovac e Astrazenica. A Sinovac é uma vacina contendo antígeno do vírus inativado com estudos de soro conversão demonstrando resultados superiores a $92 \%$ em participantes que tomaram duas doses no intervalo de 14 dias. Sua via administração é intramuscular, duas doses de 0,5 ml e intervalo de 2 a 4 semanas. Já a Astrazenica contém partículas virais do vetor adenovírus recombinante de chimpanzé, com esquema vacinal de 2 doses e 0,5 $\mathrm{ml} \mathrm{em} \mathrm{um} \mathrm{intervalo} \mathrm{de} 12$ semanas. Estudos demonstraram soro conversão em mais de 98\% dos indivíduos em 28 dias após a segunda dose (Plano Nacional de Operacionalização da Vacinação Contra a COVID-19, 2021). 
Diante do exposto, esta pesquisa almejou como objetivo principal analisar a segurança à exposição aos riscos ocupacionais dos diversos trabalhadores de saúde que atuam diretamente frente à pandemia do COVID-19 na instância de saúde do Rio de Janeiro. Já como objetivos específicos: mensurar o seu efeito e assim comparar com o alicerce ofertado pela Gestão de Saúde, visando, dessa forma, demonstrar a relevância da prevenção e promoção à saúde do trabalhador de saúde diante da pandemia do COVID-19, o que consequentemente contribuirá para a saúde social e para o desenvolvimento regional.

\section{Metodologia}

A presente pesquisa tem natureza quantitativa e de acordo com a taxinomia, em relação aos fins, trata-se de uma pesquisa descritiva, pois explica características de determinada população, estabelecendo correlações e definindo natureza, não se preocupando em explicar o fenômeno que estuda. Em relação aos meios, trata-se de uma revisão bibliográfica e aplicação de um questionário, a primeira foi feito um levantamento em normativos que tratam o tema COVID-19 e Saúde do Trabalhador, a segunda pois a limitação da pesquisa é em uma unidade, de forma detalhada (Vergara, 2016).

A técnica utilizada foi a bola de neve (snowball) a amostra investigada foi não probabilística. Buscando aproveitar as redes sociais dos entrevistados fornecendo aos pesquisadores com um conjunto maior de contatos potenciais, sendo que o processo pode ser finalizado a partir do critério de ponto de saturação (Vinuto, 2014).

O instrumento escolhido para essa pesquisa foi um questionário criado através do GoogleForms, que pode ser definido como um instrumento de coleta de dados formados por ordenadas, que de acordo com Zanella (2009) podem ser descritivas, comportamentais ou preferenciais, sendo constituídas por questões abertas ou fechadas. Este questionário é composto por 15 perguntas, que inicialmente elencam os dados pessoais dos respondentes como gênero, idade, profissão, e as demais estão voltadas para buscar responder o objetivo desta pesquisa.

Na seção inicial, temos o preenchimento obrigatório com orientações, o arquivo do consentimento livre e esclarecido (TCLE) e termo de assentimento para download e campo para manifestação seu aceite ou não em participar. Havendo, discordância em participar da pesquisa, uma mensagem de agradecimento é feita ao participante. Umas grandes vantagens é o anonimato, e o atingimento de um vasto número de pessoas em um amplo espaço geográfico não necessitam da presença física do pesquisador.

As mensagens de convite para participação no estudo (contendo o link de acesso ao instrumento de pesquisa) foram encaminhadas para a lista de contatos dos pesquisadores via e-mail, rede social e aplicativo de mensagens (WhatsApp) (Vergara, 2016). Para assegurar validade e precisão ao questionário, foram realizados pré-testes com uma pequena amostra da população de interesse - com 10 participantes em cada etapa. Essas provas preliminares objetivaram a verificação de precisão dos termos, bem como, a identificação de dúvidas ou eventuais dificuldades de compreensão e interpretação dos itens que compõem o questionário.

Foram obtidas 178 respostas, as questões foram marcadas como obrigatórias, portanto, a amostra final (sem dados ausentes) foi composta por 178 questionários válidos. A coleta ocorreu entre 03 maio de 2021 e foi finalizada em 09 de maio do mesmo ano, após 48 horas sem o recebimento de novos questionários. Os critérios de inclusão no estudo, foram profissionais de saúde maiores de 18 anos, que estejam exercendo atividade profissional na área de saúde no estado do Rio de Janeiro e possua vínculo com instituição pública ou privada de saúde.

A amostra foi composta por profissionais da área da saúde atuantes nos municípios do estado do Rio de Janeiro. A pesquisa central foi autorizada pelo Comitê de Ética em Pesquisa CAAE: 53984716.0.0000.5254 Parecer: 1.615.195 e respeita os princípios da autonomia, não-maleficência, beneficência, justiça e equidade, conforme prevê a Resolução 466/2012 do Conselho Nacional de Saúde, que dispõe sobre pesquisa envolvendo seres humanos. Para análise dos dados, foi escolhida a técnica de Análise de Correspondência Múltipla (ACM), que possibilita examinar dados categóricos (qualitativos) (Carvalho, 
2008; Kassambara, 2017; Le Roux \& Rouanet, 2010). Tal análise viabiliza utilizar procedimentos otimizados para ilustrar visualmente a similaridade e dissimilaridade entre categorias de análise.

\section{Resultados e Discussão}

Quanto a categoria profissional, ao sexo e a faixa etária: A amostra final identificou que corresponde a enfermagem $(n=70) 39 \%$, outros $(n=46) 26 \%$, fisioterapia $(n=16) 9 \%$, auxiliar ou técnico em Enfermagem $(n=13) 7 \%$, psicologia $(n=10) 6 \%$; médica $(n=9) 5 \%$, odontologia $(n=6) 3 \%$, serviço Social $(n=5) 3 \%$ e agente Comunitário de Saúde $(n=3) 2 \%$. A maioria dos participantes são do sexo feminino, cerca de $86 \%(n=153)$ e masculino $14 \%(n=25)$ e a maior parte são de 36 a 55 anos o que corresponde a $61 \%(n=109)$, de 26 a 35 anos $29 \%(n=52)$, acima de 56 anos 5\% (n=9) e de 18 a 25 anos corresponde a também $5 \%(\mathrm{n}=8)$ conforme demonstra a Tabela 1.

Tabela 1. Categoria profissional, sexo e faixa etária.

\begin{tabular}{|c|c|c|c|c|}
\hline \multirow[b]{2}{*}{ Faixa Etária } & \multirow[b]{2}{*}{ Categoria Profissional } & \multicolumn{2}{|c|}{ Sexo } & \multirow[b]{2}{*}{ Total } \\
\hline & & Feminino & Masculino & \\
\hline \multirow[t]{10}{*}{ de 26 a 35 anos } & Outros & 14 & 3 & 17 \\
\hline & Agente Comunitário de Saúde & 0 & 0 & 0 \\
\hline & Odontologia & 1 & 0 & 1 \\
\hline & Enfermagem & 25 & 1 & 26 \\
\hline & Fisioterapia & 2 & 1 & 3 \\
\hline & Serviço Social & 0 & 0 & 0 \\
\hline & Aux./Técnico em Enfermagem & 0 & 1 & 1 \\
\hline & Psicologia & 1 & 1 & 2 \\
\hline & Médica & 0 & 2 & 2 \\
\hline & Total & 43 & 9 & 52 \\
\hline \multirow[t]{9}{*}{ de 36 a 55 anos } & Outros & 16 & 8 & 24 \\
\hline & Agente Comunitário de Saúde & 3 & 0 & 3 \\
\hline & Odontologia & 3 & 1 & 4 \\
\hline & Enfermagem & 40 & 1 & 41 \\
\hline & Fisioterapia & 10 & 0 & 10 \\
\hline & Serviço Social & 4 & 1 & 5 \\
\hline & Aux./Técnico em Enfermagem & 9 & 2 & 11 \\
\hline & Psicologia & 4 & 1 & 5 \\
\hline & Médica & 5 & 1 & 6 \\
\hline
\end{tabular}


Research, Society and Development, v. 10, n. 9, e14910917780, 2021

(CC BY 4.0) | ISSN 2525-3409 | DOI: http://dx.doi.org/10.33448/rsd-v10i9.17780

Total

94

15

109

de 18 a 25 anos

Outros

3

Agente Comunitário de Saúde

0

0

Odontologia

1

Enfermagem

2

Fisioterapia

Serviço Social

Aux./Técnico em Enfermagem

0

Psicologia

Médica

0

0

Total

8

8

acima de 56 anos

Outros

Agente Comunitário de Saúde

Odontologia

Enfermagem

1

Fisioterapia

Serviço Social

0

Aux./Técnico em Enfermagem

0

1

Psicologia

2

2

Médica

1

1

Total

8

9

Total

Outros

34

12

46

Agente Comunitário de Saúde

3

3

Odontologia

5

6

Enfermagem

68

70

Fisioterapia

Serviço Social

4

Aux./Técnico em Enfermagem

10

Psicologia 


\section{Médica}

Total
153
25
9

178

Fonte: Autores.

Com relação ao regime de contrato dos respondentes e a região de atuação dos profissionais de saúde: Foram identificadas, nas informações contidas no questionário que regime CLT corresponde a 48\% (n=85), Estatutário / Servidor 24\% $(\mathrm{n}=42)$, Contrato de Serviço Temporário corresponde a 12\% ( $\mathrm{n}=22)$, autônomo/RPA 12\% ( $\mathrm{n}=22)$ e CNPJ/MEI corresponde a 4\% (n=7), Em relação ao quesito de atuação dos respondentes verificou-se que a maioria atua na cidade do Rio de Janeiro com 61,8\% ( $\mathrm{n}=110)$, nas demais, Piraí com 9\% (n=16), Niterói com 7,3\% (n=13), Nova Iguaçu com 5,6\% ( $\mathrm{n}=10)$, Duque de Caxias com 2,8\% (n=5), Itaboraí com 2,2\% (n=4), Mendes com 1,7\% (n=3). Já Itaguaí, Resende e São João de Meriti teve 1,1\% (n=2) cada uma. E por fim, Belford Roxo, Bom Jardim, Magé, Mesquita, Nilópolis, Paracambi, Queimados, Rio Bonito e Vassouras tiveram cada uma $0,6 \%(n=1)$, conforme Tabela 2 .

Tabela 2. Regime de contrato e município onde exerce profissão.

\begin{tabular}{|c|c|c|c|c|c|c|}
\hline \multirow[b]{2}{*}{ Cidade } & \multicolumn{5}{|c|}{ Regime Contratual } & \multirow[b]{2}{*}{ Total } \\
\hline & Contrato de Serviço/Temporário & CLT & $\begin{array}{c}\text { Estatutário / } \\
\text { Servidor }\end{array}$ & $\begin{array}{c}\text { Autônomo / } \\
\text { RPA }\end{array}$ & $\begin{array}{l}\text { CNPJ } \\
\text { / MEI }\end{array}$ & \\
\hline Niterói & 4 & 5 & 4 & 0 & 0 & 13 \\
\hline Rio de Janeiro & 8 & 68 & 14 & 14 & 6 & 110 \\
\hline Nova Iguaçu & 4 & 4 & 0 & 2 & 0 & 10 \\
\hline Duque de Caxias & 0 & 3 & 0 & 2 & 0 & 5 \\
\hline Mangaratiba & 1 & 0 & 1 & 0 & 0 & 2 \\
\hline Itaboraí & 0 & 1 & 2 & 1 & 0 & 4 \\
\hline Nilópolis & 0 & 1 & 0 & 0 & 0 & 1 \\
\hline São João de Meriti & 1 & 0 & 0 & 1 & 0 & 2 \\
\hline Rio Bonito & 0 & 1 & 0 & 0 & 0 & 1 \\
\hline Magé & 0 & 0 & 0 & 1 & 0 & 1 \\
\hline Mesquita & 1 & 0 & 0 & 0 & 0 & 1 \\
\hline Mendes & 2 & 0 & 1 & 0 & 0 & 3 \\
\hline Piraí & 1 & 1 & 14 & 0 & 0 & 16 \\
\hline Resende & 0 & 0 & 2 & 0 & 0 & 2 \\
\hline Belford Roxo & 0 & 0 & 1 & 0 & 0 & 1 \\
\hline
\end{tabular}




\begin{tabular}{|c|c|c|c|c|c|c|}
\hline Bom Jardim & 0 & 0 & 1 & 0 & 0 & 1 \\
\hline Paracambi & 0 & 0 & 0 & 1 & 0 & 1 \\
\hline Queimados & 0 & 0 & 1 & 0 & 0 & 1 \\
\hline Itaguaí & 0 & 0 & 1 & 0 & 1 & 2 \\
\hline Vassouras & 0 & 1 & 0 & 0 & 0 & 1 \\
\hline Total & 22 & 85 & 42 & 22 & 7 & 178 \\
\hline
\end{tabular}

Fonte: Autores.

Com relação se foi apresentado protocolo de segurança para realizar as suas atividades, pela instituição onde você trabalha:

No que tange a apresentação do protocolo de segurança, $80 \%(n=142)$ informaram que sim e $20 \%(n=36)$ informaram que não, conforme Gráfico 1.

Gráfico 1. Foi apresentado protocolo de segurança para realizar as suas atividades?

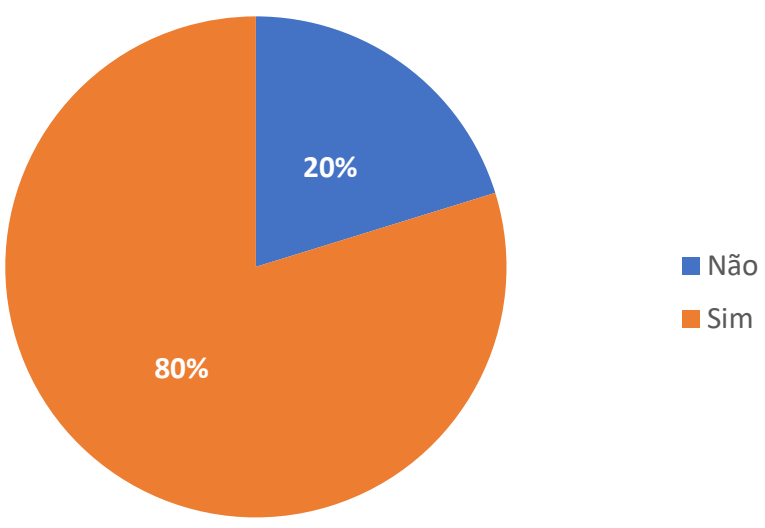

Fonte: Autores.

Com relação se está sendo implementado o protocolo de segurança para realizar as suas atividades pela instituição onde você trabalha

No que tange a implementação do protocolo de segurança para realizar as suas atividades, $80 \%$ (n=143) informaram que sim e $20 \%(n=35)$ informaram que não, conforme Gráfico 2. 
Gráfico 2. Está sendo implementado o protocolo de segurança para realizar as suas atividades pela instituição onde você trabalha.

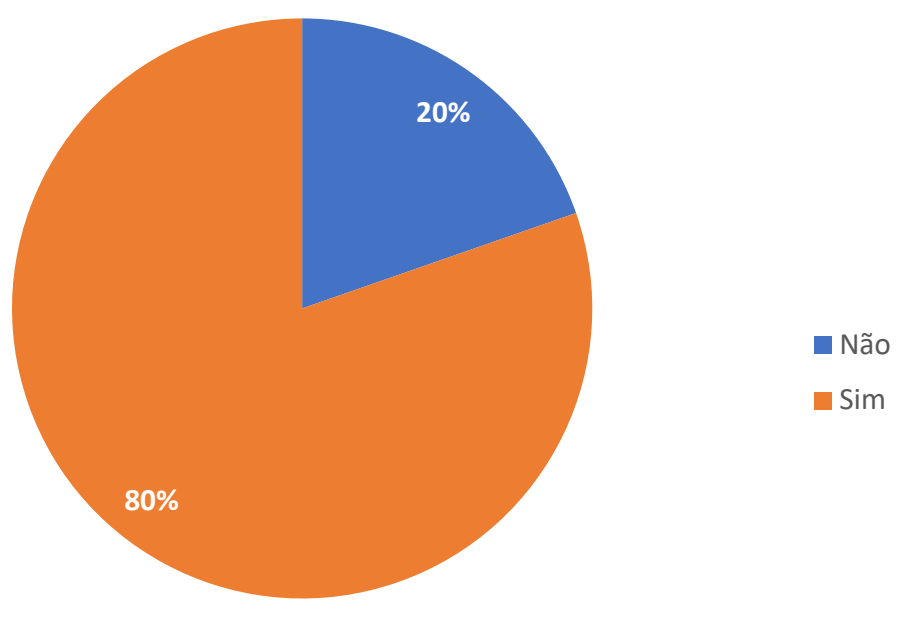

Fonte: Autores.

Com relação se foi oferecido algum suporte psicológico por conta a exposição a COVID-19 por parte da empresa.

No que tange o oferecimento de algum suporte psicológico por conta a exposição a COVID-19, 66\% ( $\mathrm{n}=117)$ informaram que NÃO e 20\% (n=35) informaram que SIM, conforme Gráfico 3.

Gráfico 3. Oferecido algum suporte psicológico por conta a exposição a COVID-19 por parte da empresa na qual você presta serviço.

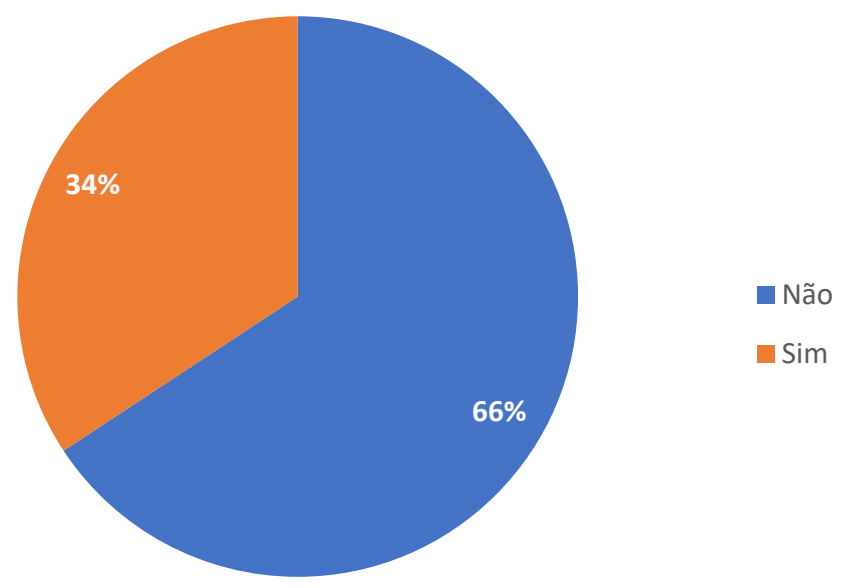

Fonte: Autores. 
No que tange o oferecido algum suporte médico ou teste por conta a exposição a COVID-19, os respondentes informaram que não tiveram nenhum suporte 36\% ( $\mathrm{n}=64$ ), que foi oferecido Teste SWAB (PCR) para COVID-19 33\% ( $\mathrm{n}=59$ ), Teste Rápido para COVID-19 11\% ( $n=20)$, Sorologia para COVID-19 8\% ( $\mathrm{n}=15)$, outros 6\% ( $\mathrm{n}=11)$ e Consulta Médica ou de Enfermagem 5\% (n=9), conforme Gráfico 4.

Gráfico 4. Oferecido algum suporte médico por conta a exposição a COVID-19 por parte da empresa na qual você presta serviço.



Fonte: Autores.

Já no que se refere se lhe foi oferecido algum suporte abaixo por conta a exposição a COVID-19 os respondentes informaram que não tiveram nenhum suporte 75\% (n=134), já transporte fretado corresponde a 13\% (n=23), outros 7\% ( $\mathrm{n}=13)$, Hospedagem Solidária foi de 2\% ( $\mathrm{n}=4$ ) e Serviço de Uber/Táxi também foi de 2\% (n=4) conforme Gráfico 5.

Gráfico 5. Oferecido algum suporte abaixo por conta a exposição a COVID-19.

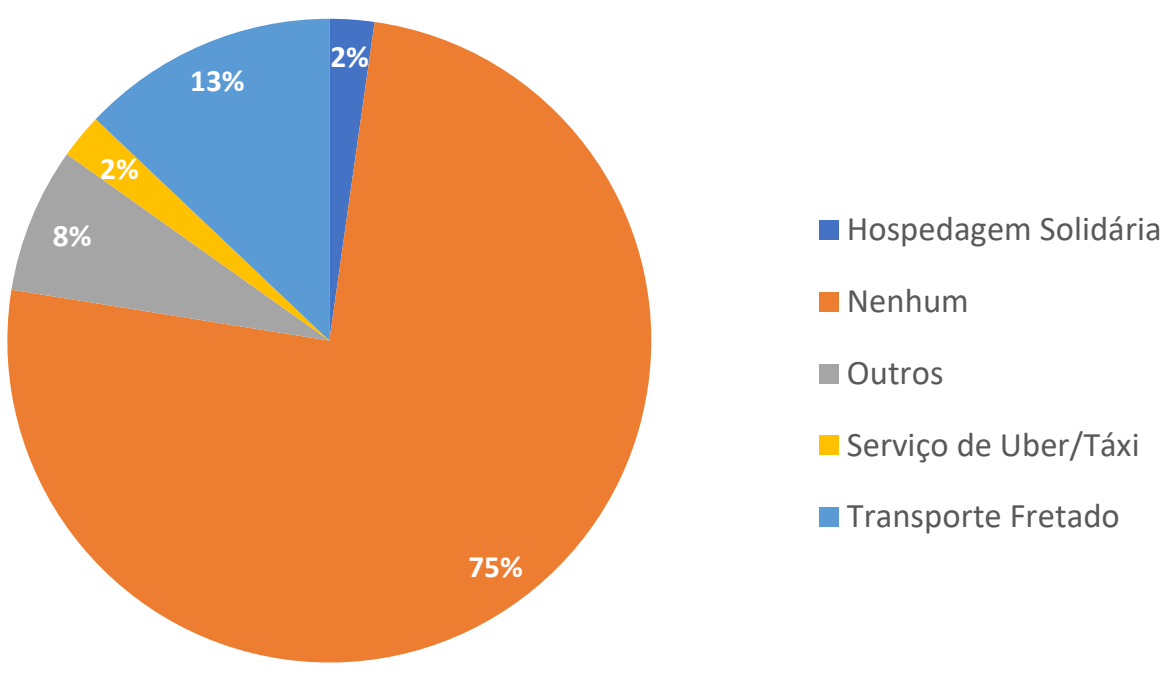

Fonte: Autores. 
Research, Society and Development, v. 10, n. 9, e14910917780, 2021

(CC BY 4.0) | ISSN 2525-3409 | DOI: http://dx.doi.org/10.33448/rsd-v10i9.17780

Com relação se os profissionais respondentes foram infectados pela COVID-19, 62\% (n=111) informaram que NÃO e $38 \%$ ( $\mathrm{n}=67)$ informaram que SIM, conforme Gráfico 6.

Gráfico 6. Você foi diagnosticado com COVID-19?

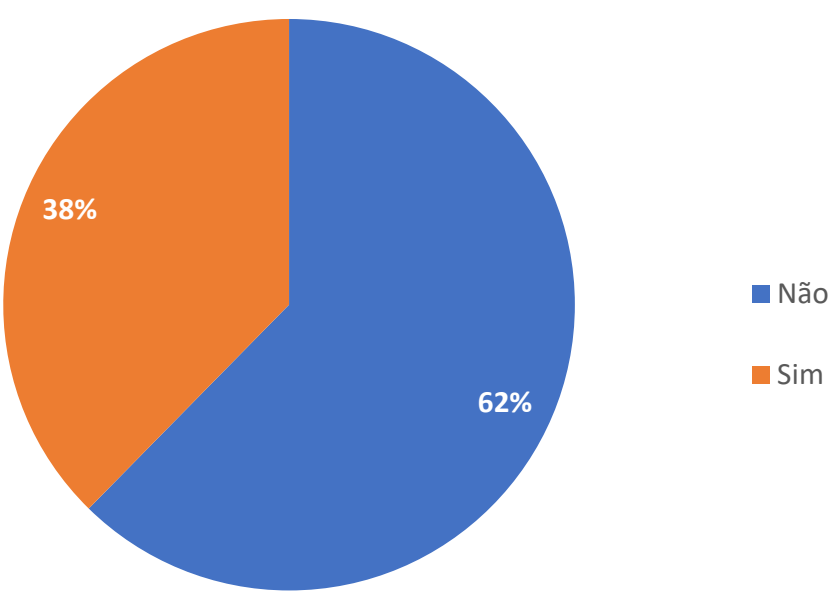

Fonte: Autores.

Com relações profissionais respondentes foram afastados das atividades presenciais, $54 \%$ ( $\mathrm{n}=96$ ) informaram que NÃO e 46\% (n=82) informaram que SIM, conforme Gráfico 7.

Gráfico 7. Afastado das atividades profissionais por conta da COVID-19?

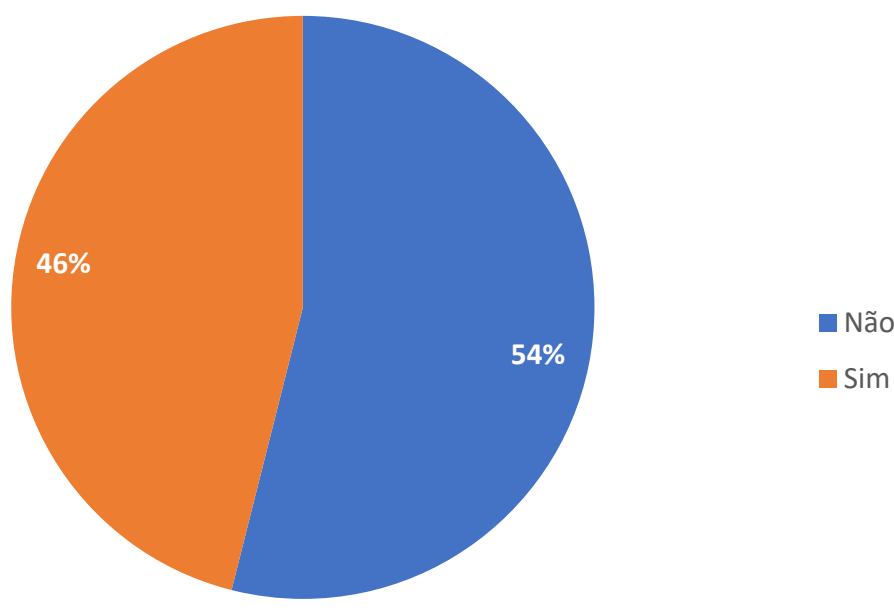

Fonte: Autores. 
Com relação se caso de afastamento, o profissional se sentiu acolhido no seu retorno nas atividades profissionais, 57\% $(n=101)$ informaram que NÃO SE APLICA, já 29\% ( $n=52)$ informaram que SIM e 14\% (n=25) informaram que NÃO, conforme Gráfico 8.

Gráfico 8. Em caso de afastamento, você se sentiu acolhido no seu retorno nas atividades profissionais.

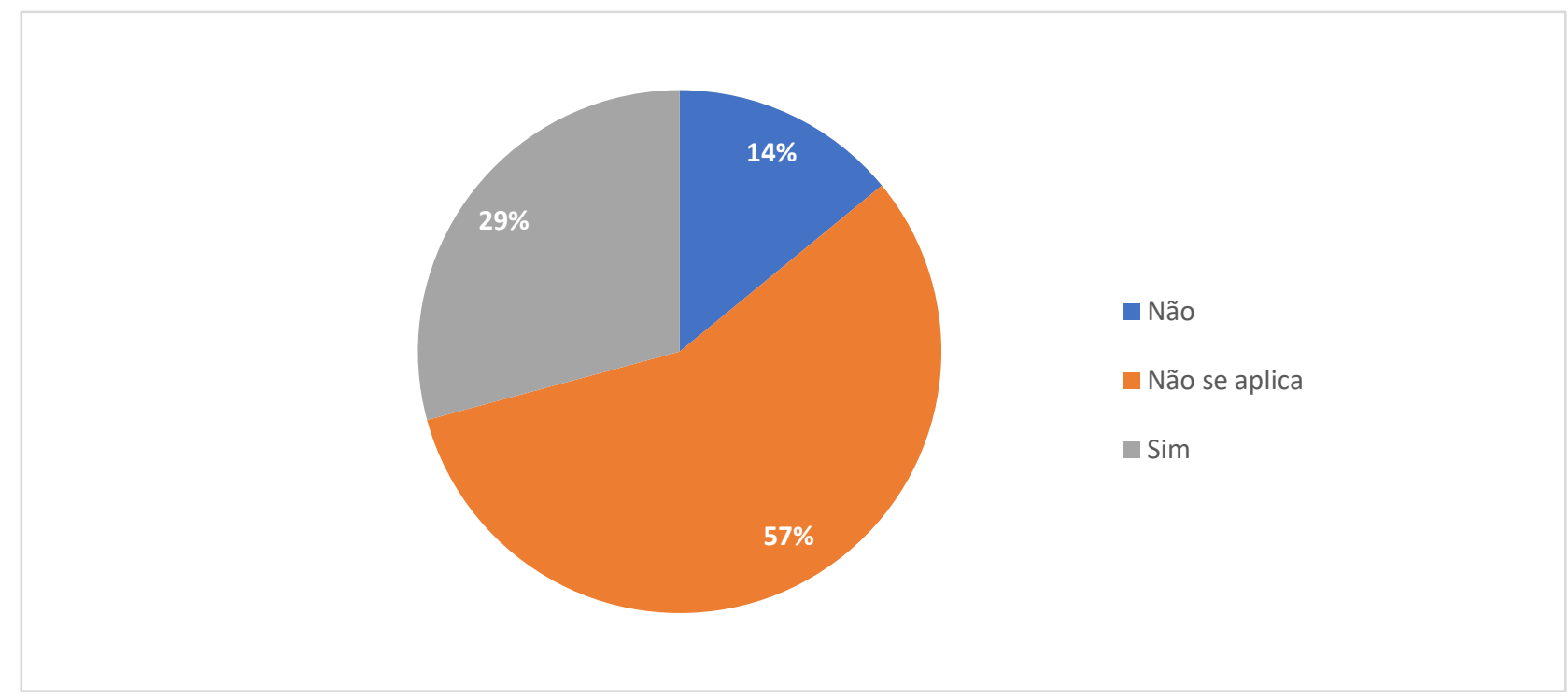

Fonte: Autores.

Com relação se os profissionais respondentes possuem plano de saúde, $79 \%$ (n=141) informaram que SIM e $21 \%$ (n=37) informaram que NÃO, conforme Gráfico 9.

Gráfico 9. Possui plano de assistência à saúde.

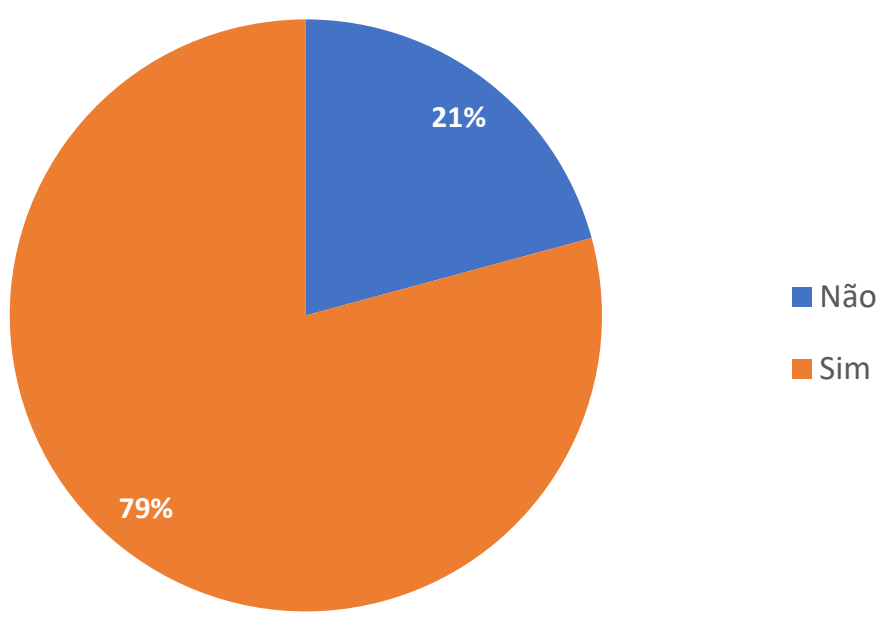

Fonte: Autores. 
Com relação se os profissionais respondentes já foram vacinados, 65\% (n=116) informaram que SIM e 35\% (n=62) informaram que NÃO, conforme Gráfico 10.

Gráfico 10. Já foi vacinado?

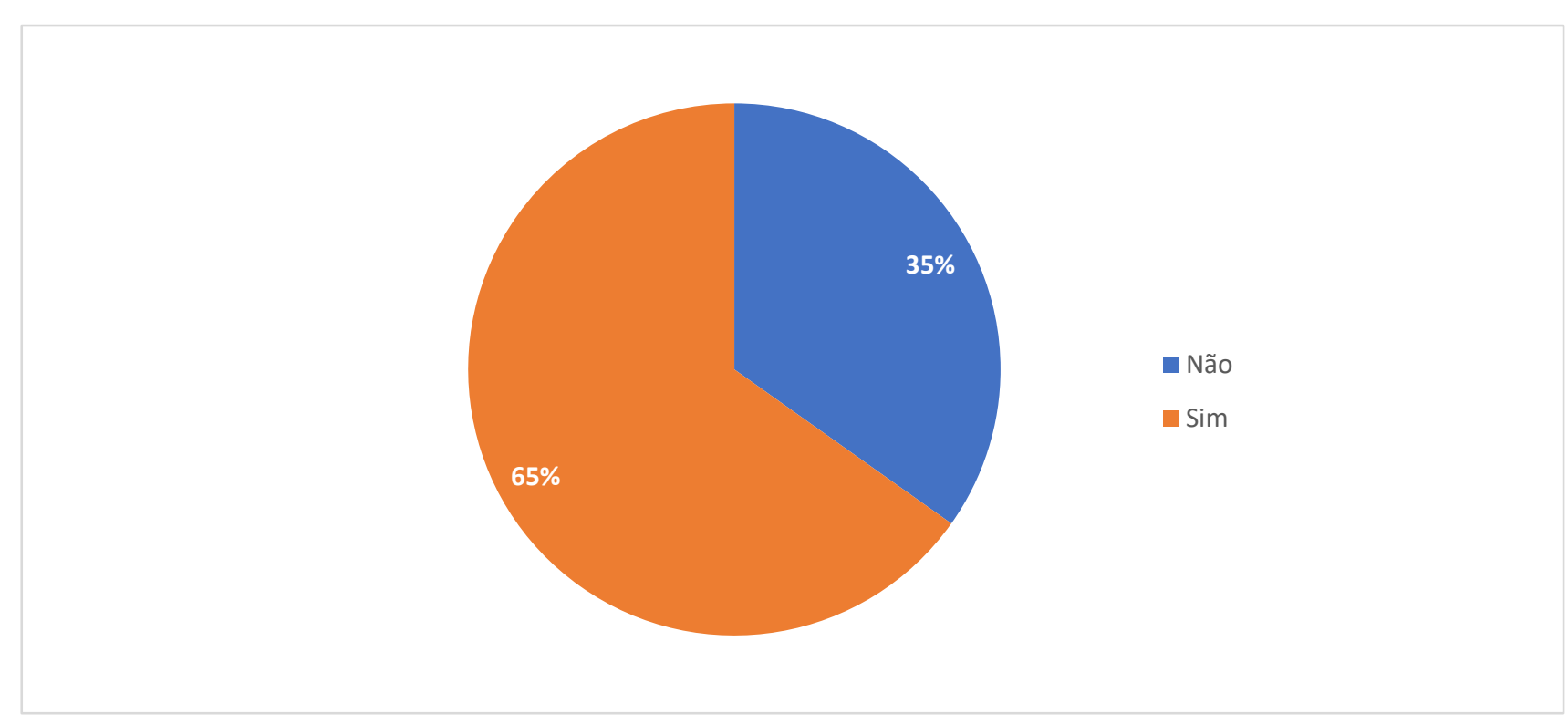

Fonte: Autores.

Já no que se refere a ACM, a variável COVID é suplementar não influencia na análise das dimensões, neste caso observamos como os indivíduos se sobrepõem no gráfico e em relação a variável da COVID-19. Quanto mais próximo da origem (eixo 0,0) maior a frequência dos dados para esta categoria.

Nos dados coletados foi possível encontrar 3 grupos, sendo 2 bem definidos. 
Figura 1. Mapa da Análise Correspondência Múltipla.

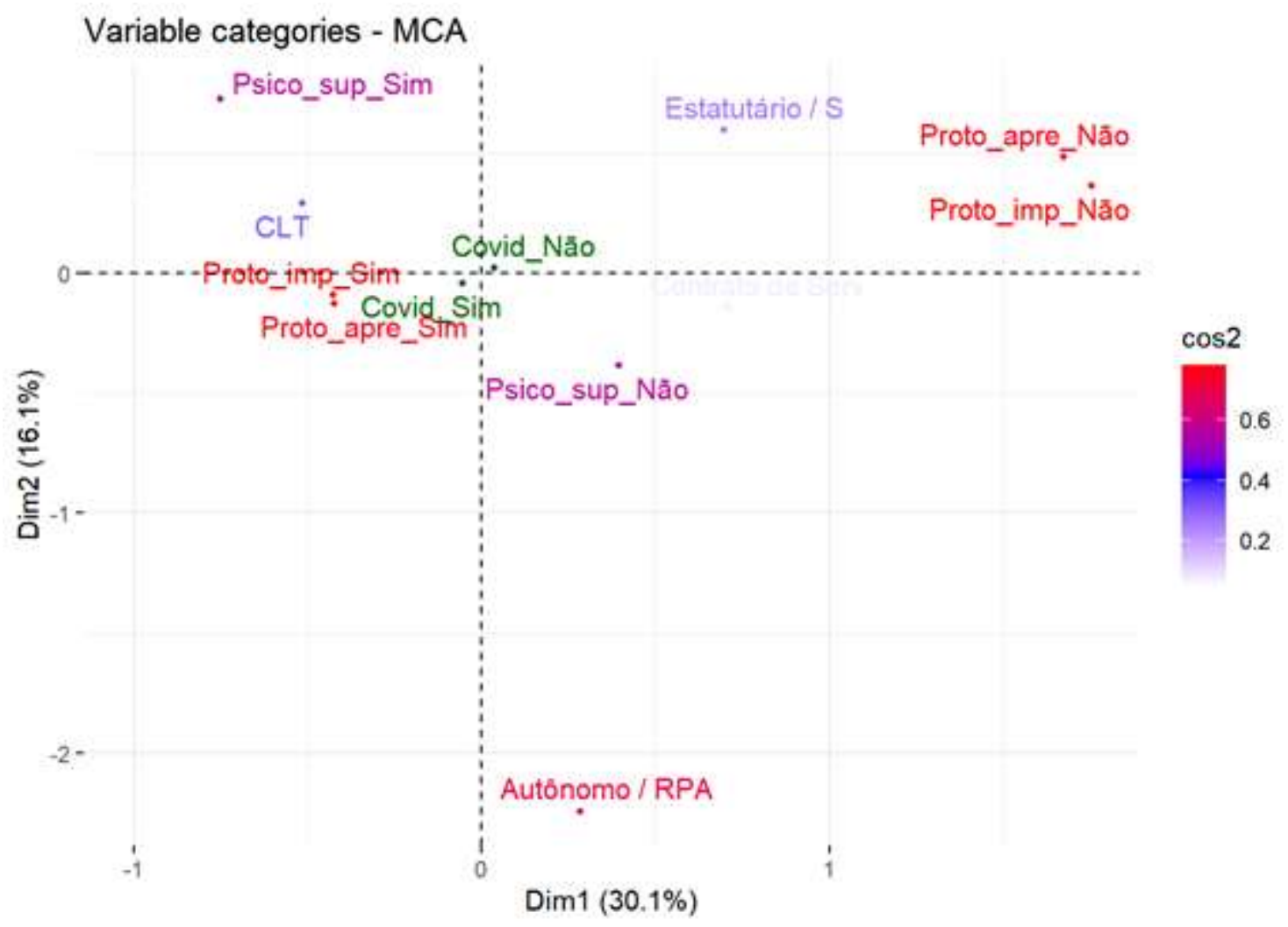

Fonte: Autores.

Percebe-se que as empresas com funcionários celetistas apresentaram protocolos de segurança, implementaram protocolos e algumas empresas ofereceram suporte psicológico. O outro grupo, as instituições não adotaram protocolos e algumas não implementaram suporte psicológico, sendo possível observar que o regime mais comum foi de servidores e estatutários e alguns temporários. O terceiro grupo afastado dos protocolos estão os autônomos e RPA. É percebido através destes dados que as empresas particulares, foram cobradas em expor os protocolos de segurança recomendados pelo OMS e Ministério da Saúde do que os profissionais liberais

A variável suplementar COVID-19 indica que a maior frequência dos contaminados estão ao lado do grupo dos respondentes que trabalham em regime de celetista, possivelmente por terem sido mais expostos à contaminação do que os demais. Um indicativo disso, pode estar relacionado com o aumento do número de atendimento na rede que adotou esse regime de trabalho, outro ponto a população entrevista em sua maioria tem como regime de trabalho a CLT.

Os enfermeiros, sendo maior número de participantes desse estudo. Apesar haver a necessidade de identificar os profissionais que estão diretamente na linha de frente, para que esses recebam os cuidados necessários para manter a qualidade de atendimento à população". (de Lima Barroso et al., 2020, p. 11), os profissionais de enfermagem de diversas especialidades têm investidos esforços, principalmente na inteligência emocional, para estabelecer relações empáticas com a população infectada com a COVID-19. É sabido que a enfermagem atua diretamente na assistência em todas as esferas e especialidades (Amestoy, 2020).

A maior parte da população estudada é do gênero feminino, dentre a faixa etária da amostra da população, têm de 36 a 55 anos. Malta et al. (2019) fala da prevalência de diabetes em mulheres de 40 a 49 anos, que é crescente quando comparadas com a população brasileira. Já Valentini, et al. (2020) nos mostra que os profissionais de enfermagem por conta dos fatores de 
estresse diário com a insatisfação profissional, podem interferir ainda mais no desenvolvimento dos fatores de risco das doenças cardiovasculares. O que nos mostra que os profissionais de saúde da categoria de enfermagem que nesse estudo está em maioria e as que estão dentro da faixa etária de 40 a 49 anos tem um grande risco de terem uma doença cardiovascular e ou diabetes. Essas comorbidades são fatores de riscos relacionados ao COVID-19. Logo os profissionais dessa categoria teriam um risco elevado de agravamento caso contaminados com a COVID-19. (Feitoza et al. 2020).

Dentro da amostragem realizada neste estudo, $20 \%$ dos participantes sinalizaram que não foram apresentados os protocolos de segurança para realizarem suas atividades funcionais. Bezerra et al. (2020) já viera ressaltar essa problemática ao abordar sobre a falta de treinamento para novos protocolos a serem adotados. Embora o número mais expressivo tenha evidenciado que houve a atuação da instituição nesse aspecto, ainda sim, é preciso considerar o índice inferior apresentado, haja vista o grau de exposição desses profissionais, bem como a importância e o reconhecimento da atividade laborativa exercida como bem descreve de Lima Barroso et al. (2020) e o seu papel assumido enquanto protagonista como destacado por Aragão, Souza, Vieira e Reis (2020). O Ministério da Saúde (2020) através do instrumento que recomenda a proteção dos trabalhadores dos serviços da saúde elenca a essencialidade do olhar frente a segurança e saúde em ambiência institucional, dando foco aos profissionais e sua formação nesse quesito. Neste mesmo viés, a Política Nacional de Saúde do trabalhador e da trabalhadora determina a atenção integral à saúde destes, advinda de iniciativas com caráter de promoção e proteção.

Em relação aos protocolos de segurança não estão sendo implementados de maneira satisfatória no exercício profissional por intermédio das instituições. Dos Santos e de Azevedo (2020) apontam que o risco de infecção decorrente da falta de materiais e o inadequado fornecimento de EPI contribui para os impactos e incertezas no fazer profissional do trabalhador da saúde. O Ministério da Saúde (2020) ratifica a necessidade do uso de EPIs para a redução dos riscos de contaminação do vírus, nesse sentido os empregadores devem fornecer em quantidade e qualidade como medida de proteção coletiva, devendo ser considerado o seu uso racional frente a sua alta demanda de forma global. Olaru et al., (2021) perpassam por este debate, contudo buscando evidenciar sobre a importância da racionalização dos EPIs em ambientes de saúde, ao passo que se torna preciso realizar a avaliação de risco a qual o profissional está exposto em seu lugar de atuação, constata que nem todos serão indicativos para a utilização da totalidade dos materiais de segurança, dessa forma estaria contribuindo para a redução dos lixos hospitalares e a diminuição da escassez desses equipamentos de proteção. Neste viés, Hick, Hanfling, Wynia e Pavia (2020) apontam técnicas de conservação e reaproveitamento adotadas de forma adicional no caso de ausência dos EPI como nova prática a ser incorporada.

Frente ao prisma, voltada à atenção psicológica do profissional da saúde, evidencia que mais de $50 \%$ dos correspondentes sinalizaram que as instituições às quais estavam vinculadas não prestaram apoio psicológico pós-exposição a COVID-19. Para Bezerra et al. (2020) a COVID-19 e seus impactos na saúde mental dos trabalhadores da saúde vem acarretar resultados negativos à eficácia da atividade laboral, trazendo implicações inclusive que contribui para o desenvolvimento do transtorno de estresse pós-traumático. Neste aspecto Teixeira et al. (2020) vem elucidar sobre a criação de equipes que possam fornecer o apoio psicológico dos trabalhadores da área da saúde. A materialização de ações voltadas para a atenção psicossocial e a promoção da saúde mental aos profissionais da saúde torna-se essencial para a redução dos impactos causados na vida destes. Ações como o acolhimento, o atendimento preventivo e aquele relacionado ao momento de crise vem contribuir para a saúde mental. Enquanto estratégias de atendimento à saúde mental aos trabalhadores da saúde, estes autores destacam as ações de primeiros cuidados psicológicos que poderá ser ofertada on-line e presencial, ao mesmo tempo que relaciona as formas de prestação dos serviços podendo ser através da telemedicina, aplicativos e atendimento on-line e virtual.

Dos participantes do estudo 36\%, informaram que não receberam nenhum suporte médico por parte da empresa devido a exposição a COVID-19. Helioterio et al. (2020), vêm contribuir neste quesito ao elencar em seu estudo, estratégias de atuação desse cuidado junto aos profissionais de saúde, sendo elas: a testagem, o atendimento especializado e o apoio e suporte na atenção 
psicossocial, bem como o treinamento sobre COVID-19 e seus aspectos relacionados, os EPIs e sua utilização, a carga horária de trabalho, a atenção sobre os fluxos de atendimento (Senna et al. 2016; Pinto, 2020).

Outro dado exposto que 75\% desses participantes não receberam um suporte que se facilita o deslocamento para o local de trabalho e muito menos hospedagem solidária, para que os profissionais pudessem proteger os seus familiares de convívio direto. Esses também podem ser considerados uma oferta de suporte, podendo assim promover a saúde, já estes englobam a preocupação com as questões físicas e psicológicas (Teixeira et al. 2020; Gonçalves et al. 2021).

Da população que participou do estudo $62 \%$ não foi diagnóstica com COVID-19, quando comparamos com outros dados do estudo onde somente 11\% realizaram Teste Rápido para COVID-19 e sorologia somente 8\% dos participantes, traz a reflexão se realmente os profissionais passaram por uma boa avaliação, também indicando que não houve rastreio, para possíveis profissionais assintomáticos, neste sentido, estas medidas de prevenção e controle são relevantes principalmente porque a síndrome pode não estar presente e, assim, pode afetar o controle da propagação da infecção e doença pelo novo coronavírus (ANVISA, 2021). Segundo Sant'Ana et al. (2020), o número de profissionais infectados variou de 1.716 a 17.306. de acordo com cada país.

Outro ponto que $54 \%$ dos trabalhadores da saúde não foram afastados do trabalho por conta da COVID-19, embora existam procedimentos relacionados à saúde desse grupo de trabalhadores que são obrigatórios e regulamentados (Cunha et al., 2021).

Os profissionais que foram afastados responderam não se sentirem acolhidos após o retorno às atividades profissionais, o acolhimento é um dos pressupostos que norteia as políticas do SUS e sua prioridade tem como o foco o paciente. Nesse momento, o profissional de saúde também é o "paciente", ou seja, esse trabalhador também precisa ser considerado dentro desses pressupostos. Pois são estes que estão na linha de frente que poderão ou não proporcionar a qualidade dos serviços prestados, para isso eles devem ser cuidados, para cuidar de maneira efetiva (de Lima Barroso et al. 2020).

Embora venha evidenciar que 65\% dos respondentes possuem plano de saúde, convém pontuar que os planos de saúde vêm oferecer cobertura para um número considerado da população, contudo, este não é um serviço acessível a todos os cidadãos, frente ao seu alto custo e determinadas burocracias exigidas no momento primordial do cuidado à saúde, como é o caso de um atendimento de alta complexidade. Dessa forma, o acesso ao plano de saúde privado é permeado por fatores relacionados às condições econômicas. Altas taxas, exige de um serviço prestado a qualidade exemplar, contudo este fato não corresponde à realidade em sua totalidade. Já o Sistema Único de Saúde- SUS atua em seus diversos tipos de atenção à Saúde, sendo considerado em seus princípios a universalidade, a integralidade e a equidade. Desta forma, todos os cidadãos, até mesmo aqueles com plano de saúde utilizam o SUS (Salazar et al. 2006).

Já o dado que foi referido, 35 \% desses entrevistados não receberam a vacina contra a COVID-19, mesmo diante da exposição direta a pacientes suspeitos ou confirmados para COVID-19, o que evidencia o maior risco de adoecimento (Silva et al. 2016). Mesmo a NR32 evidenciando a importância das vacinas para os profissionais de saúde, pela questão de logística a um grande enfrentamento em relação ao direito a vacina para os profissionais.

\section{Considerações Finais}

A atuação dos trabalhadores da saúde é elemento central no enfrentamento da pandemia da COVID-19, nesse sentido esta pesquisa buscou identificar o reconhecimento deste ponto fundante a partir das investidas e respostas aos riscos ocupacionais frente à saúde deste trabalhador.

Destaca-se que as abordagens e intervenções promovidas pelas instituições, no que diz respeito a apresentação e implantação ao protocolo de segurança, suporte material e psicológico aos profissionais de saúde ocorreram, mas não em sua totalidade, permeando nestes trabalhadores a sensação de vulnerabilidade associadas ao temor de que algo ruim possa ocorrer a 
si e aos outros, uma vez que não existe uma efetividade na apresentação dos protocolos de segurança, e com isso, o aumento da demanda nos serviços de saúde, bem como a perda de controle sobre os acontecimentos que acaba gerando impactos negativos no funcionamento psíquico e cognitivo desses profissionais. Os profissionais devem se sentir protegidos e acolhidos em sua função laborativa, tanto no que tange a visão coletiva do trabalho, quanto nos seus aspectos individuais, pois para a execução de uma atividade e prestação de serviço, visando a qualidade, é preciso considerar o bem-estar do funcionário.

Os protocolos de segurança existem para o seu cumprimento, sendo necessário estabelecer critérios para a sua fiscalização e efetivação, por conseguinte, torna-se oportuno reforçar sobre a indispensável garantia dos EPIs, pois a falta desses equipamentos vem acarretar consequências agravantes, gerando maior vulnerabilidade nas ações de combate à pandemia. Não obstante, ressalta-se que a análise aqui traçada pretende ir além da determinação da apresentação e oferta pontual de EPIs por intermédio da instituição empregadora, e sim demonstrar a importância de se pensar a força de trabalho exercida pelos profissionais de saúde considerando suas múltiplas aflições e concebendo as características exógenas e endógenas do indivíduo que influi neste processo de saúde/doença. Esta pesquisa evidenciou a fragilidade da concepção e atuação a partir da atenção à saúde de forma integral investida ao público aqui específico, expondo assim, a necessidade de haver a evolução neste quesito, primando por iniciativas com caráter de promoção e proteção, pois estes profissionais irão atuar frente as mazelas geradas por este vírus que assola toda a sociedade nos tempos atuais, dentre outras doenças existente em sua linha de atuação.

Destarte que essa pesquisa contribuiu para elucidar que a realidade atual e seus impactos vem demonstrando que se torna emergente a necessidade de investir ou de continuar investindo na saúde e bem-estar dos profissionais, bem como na capacitação e estratégias para se pensar saúde do trabalhador, pois intervindo no público que cuida, estaríamos contemplando aqueles que serão alvo de seus cuidados.

Diante do exposto, a leitura do presente artigo pode auxiliar pesquisadores da área de gestão em saúde de pessoas a compreenderem melhor como as instituições de saúde e combate a pandemia vem abordando as práticas de protocolo de segurança, bem como sua evolução teórica. O escopo deste artigo apresentou pesquisas atuais bem como suas descrições, assim, com base nas definições recentes sobre o referido tema, pesquisadores da área podem se debruçar nas conclusões desse artigo para avançarem em seus estudos, bem como utilizar os resultados aqui alcançados para a realização de pesquisas empíricas, investigando se a opinião dos profissionais está alinhada com as definições dos protocolos de segurança determinadas de forma nacional e/ou mundial.

\section{Referências}

Agência Nacional de Vigilância Sanitária- ANVISA (2021, fevereiro 25). Nota técnica GVIMS/GGTES Anvisa N²04/2020. https://www.gov.br/anvisa/ptbr/centraisdeconteudo/publicacoes/servicosdesaude/notas-tecnicas/nota-tecnica-gvims_ggtes_anvisa-04_2020-25-02-para-o-site.pdf>.

Amestoy, S. C. (2020). Inteligência emocional: habilidade relacional para o enfermeiro-líder na linha de frente contra o novo Coronavírus/Emotional intelligence: relationship skill for the nurse-leader on the front line against the new Coronavirus. Journal of Nursing and Health, 10(4).

Aragão, J. A., Souza L. R. D., Vieira, B. H., \& Reis, F. P. (2020). Impactos na saúde mental dos profissionais de saúde no enfrentamento da COVID-19. In: COVID-19: o trabalho dos profissionais da saúde em tempos de pandemia/Organizadora Samylla Maira Costa Siqueira, - Guarujá, SP: Científica Digital.

Barello, S., Palamenghi, L., \& Graffigna, G. (2020). Burnout and somatic symptoms among frontline healthcare professionals at the peak of the Italian COVID19 pandemic. Psychiatry research, 290, 113129.

Bezerra, G. D., Sena, A. S. R., Braga, S. T., dos Santos, M. E. N., Correia, L. F. R., de Freitas Clementino, K. M., ... \& Pinheiro, W. R. (2020). O impacto da pandemia por COVID-19 na saúde mental dos profissionais de saúde: revisão integrativa. Revista Enfermagem Atual In Derme, 93.

Brasil. (2012). Portaria $\mathrm{n}^{\circ}$ 1.823, de 23 de agosto de 2012. Institui a Política Nacional de Saúde do Trabalhador e da Trabalhadora. Diário Oficial da União, 1 , 46-51.

Campion, J., Javed, A., Sartorius, N., \& Marmot, M. (2020). Addressing the public mental health challenge of COVID-19. The Lancet Psychiatry, 7(8), 657659. 
Carvalho, H. (2008). Análise Multivariada de Dados Qualitativos: Utilização da Análise de Correspondências Múltiplas com o SPSS. Edições Silabo. Lisboa.

Conselho Nacional de Saúde- CNS (2020). Recomendação n 020. 2020. http://conselho.saude.gov.br/recomendacoes-cns/1103-recomendac-a-o-no-020-de-07de-abril-de-2020>.

Conselho Regional de Enfermagem de São Paulo (COREN-SP). (2017). Guia para a Construção de Protocolos Assistenciais de Enfermagem. https://portal.corensp.gov.br/sites/default/files/Protocolo-web.pdf.

Cunha, D. de O. da, Souza, R. C. B., Gonçalves, C. P., \& Barbosa, A. M. da C. (2021). Saúde indígena e transculturalidade em tempos de covid-19: um estudo de caso na aldeia Tupinambá. Revista AlembrA, 3(6), 131-151. https://doi.org/10.47270/RA.2596-2671.2021.v3.n6.id1090

da Silva Veloso, R. S. (2020). Burnout nos profissionais de saúde durante a pandemia COVID-19.

de Lima Barroso, B. I., de Souza, M. B. C. A., Bregalda, M. M., Lancman, S., \& da Costa, V. B. B (2020). Saúde do Trabalhador em Tempos de Covid-19: Reflexões Sobre Saúde, Segurança e Terapia Ocupacional.

dos Santos, T. T. S., \& de Azevedo, M. M. (2020). A continuidade da assistência no trauma durante a pandemia de COVID-19. In: COVID-19: o trabalho dos profissionais da saúde em tempos de pandemia/Organizadora Samylla Maira Costa Siqueira, - Guarujá, SP: Científica Digital.

Feitoza, T. M. O., Chaves, A. M., Muniz, G. T. S., da Cruz, M. C. C., \& Junior, I. D. F. C. (2020). COMORBIDADES E COVID- 19. Revista Interfaces: Saúde, Humanas e Tecnologia, 8 (3), 711- 723. http://dx.doi.org/10.16891/2317 - 434X.v8.e3.a2020. pp711 - 723.

Gonçalves, C. P., Luna, C. P., da Cunha, D. D. O., de Sinay, M. C. F., \& Ayrosa, E. A. T. (2020). Gênero, Violência e Políticas Públicas: Uma Análise Acerca dos Homicídios de Mulheres na Região Sudeste Entre 2003-2014/Gender, Violence and Public Policies: An Analysis of Women's Homicides in the Southeast Region Between 2003-2014. Revista FSA (Centro Universitário Santo Agostinho), 17(10), 381-398.

Guimarães, R. (2021). Vacinas: Da Saúde Pública ao Big Business. Ciência \& Saúde Coletiva, 26, 1847-1852.

Helioterio, M. C., Lopes, F. Q. R. D. S., Sousa, C. C. D., Souza, F. D. O., Pinho, P. D. S., Sousa, F. N., \& Araújo, T. M. D. (2020). Covid-19: Por que a proteção de trabalhadores e trabalhadoras da saúde é prioritária no combate à pandemia?. Trabalho, Educação e Saúde, 18.

Informe, E. N. S. P. (2021). Fiocruz desenvolve novas vacinas para enfrentar Covid-19.

Kassambara, A. (2017). Practical guide to principal component methods in R: PCA, M (CA), FAMD, MFA, HCPC, factoextra (Vol. 2). Sthda.

Le Roux, B., \& Rouanet, H. (2010). Multiple correspondence analysis (Vol. 163). Sage.

Lopes, P. D. L. J. M., \& da Silva, M. (2021). Ministério da Saúde.

Malta, D. C., Duncan, B. B., Schmidt, M. I., Machado, Í. E., Silva, A. G. D., Bernal, R. T. I., ... \& Szwarcwald, C. L. (2019). Prevalência de diabetes mellitus determinada pela hemoglobina glicada na população adulta brasileira, Pesquisa Nacional de Saúde. Revista Brasileira de Epidemiologia, 22, E190006-SUPL.

Melo, B. D., Pereira, D. R., Noal, D. da S., Serpeloni, F., Kabad, J. F., Kadri, M., ... \& Rabelo, I. V. M. R. (2020a). Gestão e organização dos serviços e dos cuidados em saúde. Recomendações Gerais. In D. da S. Noal, M. F. D. Passos \& C. M. de Freitas (Orgs.). Recomendações e orientações em saúde mental e atenção psicossocial na COVID-19 (23. ed. pp. 20- 27) Rio de Janeiro: Fiocruz.

Melo, B. D., Pereira, D. R., Noal, D. da S., Serpeloni, F., Kabad, J. F., e Souza, M. S., \& Rabelo, I. V. M. (2020b). Gestão e organização dos serviços e dos cuidados em saúde. Recomendações para os Gestores. In D. da S. Noal, M. F. D. Passos \& C. M. de Freitas (Orgs.). Recomendações e orientações em saúde mental e atenção psicossocial na COVID-19 (23. ed. pp. 20- 27) Rio de Janeiro: Fiocruz.

Ministério da Saúde (2020). Recomendações de proteção aos trabalhadores dos serviços de saúde no atendimento de COVID-19 e outras síndromes gripais (Abr. 2020). COE/SVS/MS

Ministério da saúde. (2021). Sobre a doença.: https://coronavirus.saude.gov.br/sobre-a-doenca.

Norma Regulamentadora- NR-32 - Segurança e Saúde no Trabalho em Serviços de Saúde- Atualizada em 2019. https://alextinoco.com/seguranca-dotrabalho/norma-regulamentadora-nr-32-enit-seguranca-e-saude-no-trabalho-em-servicos-de-saude-atualizada-2019/> .

Olaru, I. D., Ferrand, R. A., Magwenzi, M. T., Robertson, V., Musenyereki, V., \& Kranzer, K. (2021). Risk assessment for rationalizing the use of personal protective equipment for SARS-CoV2 in healthcare settings with special focus on low-and middle-income settings. Clinical Microbiology and Infection, 27(2), $169-171$.

Pinto, C. A. S. (2020). Knowledge management as a support for supply chain logistics planning in pandemic cases. Brazilian Journal of Operations \& Production Management, 17(3), 1-11.

Plano Nacional de Operacionalização da Vacinação Contra a Covid-19 (2021). Sistema Único de Saúde. Ministério da Saúde. $7^{\text {a }}$ Edição. Brasília/DF. < https://www.gov.br/saude/pt-br/coronavirus/publicacoes-tecnicas/guias-e-planos/plano-nacional-de-vacinacao-covid-19/view>.

Revista Preven (2020, junho 3). NR 32 traz orientações preventivas aos serviços de saúde na pandemia. Disponível em: < https://revistapreven.org/06/2020/covid-19/nr-32-traz-orientacoes-preventivas-aos-servicos-de-saude-na-pandemia/>. Acesso em: 14 de mai. 2021.

Rizzo, C., Campagna, I., Pandolfi, E., Croci, I., Russo, L., Ciampini, S., ... \& Ciofi Degli Atti, M. L. (2021). Knowledge and Perception of COVID-19 Pandemic during the First Wave (Feb-May 2020): A Cross-Sectional Study among Italian Healthcare Workers. International Journal of Environmental Research and Public Health, 18(7), 3767.

Salazar, A., Rodrigues, K. G., Silver, L., \& Scheffer, M. (2006). O SUS pode ser o seu melhor plano de saúde. In O SUS pode ser o seu melhor plano de saúde (pp. 67-67). 
Research, Society and Development, v. 10, n. 9, e14910917780, 2021

(CC BY 4.0) | ISSN 2525-3409 | DOI: http://dx.doi.org/10.33448/rsd-v10i9.17780

Sant'Ana, G., Imoto, A. M., Amorim, F. F., Taminato, M., Peccin, M. S., Santana, L. A., ... \& Camargo, E. B. (2020). Infecção e óbitos de profissionais da saúde por COVID-19: revisão sistemática. Acta Paulista de Enfermagem, 33.

Secretaria de Atenção Primária à Saúde (SAPS-2020). Protocolo de manejo clínico do novo coronavírus (COVID-19) na Atenção Primária à Saúde (Versão 8). Brasília: Ministério da Saúde.

Senna, P., Pinha, D., Ahluwalia, R., Guimarães, J. C., Severo, E., \& Reis, A. (2016). A three-stage stochastic optimization model for the Brazilian biodiesel supply chain. Production, 26, 501-515.

Shah, M., Roggenkamp, M., Ferrer, L., Burger, V., \& Brassil, K. J. (2021). Mental Health and COVID-19: The Psychological Implications of a Pandemic for Nurses. Clinical journal of oncology nursing, 25(1), 69-75.

Silva, L. C. S., Carrijo, F. M. M., Palos, M. A. P., Barreto, R. A. S., \& Suzuki, K. (2016). Conhecimento e Percepção dos Trabalhadores de Saúde Sobre Colonização por Microrganismos Multirresistentes. Saúde \& Ciência em Ação, 2(2), 31-43.

Teixeira, C. F. D. S., Soares, C. M., Souza, E. A., Lisboa, E. S., Pinto, I. C. D. M., Andrade, L. R. D., \& Espiridião, M. A. (2020). The health of healthcare professionals coping with the Covid-19 pandemic. Ciência \& Saúde Coletiva, 25, 3465-3474.

Valentini, A. B., Veloso, F. C., Abuchaim, É. D. S. V., Santos, V. B., \& de Lima Lopes, J. (2020). Fatores de risco cardiovascular modificáveis em profissionais de enfermagem do setor de cardiologia: estudo transversal. Revista Eletrônica de Enfermagem, 22.

Vergara, S. C. (2016). Projetos e relatórios de pesquisa em administração (16o ed). São Paulo: Editora Atlas.

Vinuto, J. (2014). A amostragem em bola de neve na pesquisa qualitativa: um debate em aberto. Temáticas, 22(44), 203-220.

Zanella, L. C. H. (2009). Metodologia de estudo e de pesquisa em administração. Florianópolis: Departamento de Ciências da Administração/UFSC, 129-149. 